\title{
QUEEN'S
UNIVERSITY
BELFAST
}

\section{A comparative analysis of the SF-12 and the SF-36 among ischaemic heart disease patients.}

Dempster, M., \& Donnelly, M. (2001). A comparative analysis of the SF-12 and the SF-36 among ischaemic heart disease patients. Journal of Health Psychology, 6 (6)(6), 707-711.

https://doi.org/10.1177/135910530100600608

Published in:

Journal of Health Psychology

Document Version:

Early version, also known as pre-print

Queen's University Belfast - Research Portal:

Link to publication record in Queen's University Belfast Research Portal

\section{General rights}

Copyright for the publications made accessible via the Queen's University Belfast Research Portal is retained by the author(s) and / or other copyright owners and it is a condition of accessing these publications that users recognise and abide by the legal requirements associated with these rights.

Take down policy

The Research Portal is Queen's institutional repository that provides access to Queen's research output. Every effort has been made to ensure that content in the Research Portal does not infringe any person's rights, or applicable UK laws. If you discover content in the Research Portal that you believe breaches copyright or violates any law, please contact openaccess@qub.ac.uk. 
Running head: COMPARING THE SF-12 AND THE SF-36

A Comparative Analysis Of The SF-12 And The SF-36 Among Ischaemic Heart Disease Patients

\author{
Martin Dempster ${ }^{1}$ \\ Michael Donnelly ${ }^{2}$
}

${ }^{1}$ School of Psychology, Queen's University Belfast

${ }^{2}$ Faculty of Medicine \& Health Science, Queen's University Belfast 
A Comparative Analysis Of The SF-12 And The SF-36 Among Ischaemic Heart Disease Patients

Abstract

This paper investigated whether the SF-12 could replace the SF-36 in the measurement of health status among ischaemic heart disease patients. The SF-36 and SF-12 were administered to 105 cardiac patients. The SF-36 summary scores were strongly correlated and similar to the SF-12 summary scores. Also, the SF-12 scores were as powerful as the SF-36 summary scores in discriminating between subgroups of patients categorised according to their self-reported health status or angina classification. It is suggested that when there is a need to collect routine information about cardiac patients' general physical and mental health, the SF-12 is preferable to the SF-36 because of its brevity and acceptability to patients.

Key words: quality of life, outcome measurement, heart disease

Biographical note:

Martin Dempster is a lecturer in psychology, with research interests in health outcome measurement and the quality of life of people with heart disease. Michael Donnelly is a reader in health services research, with research interests in health outcome measurement and community care. 
A Comparative Analysis Of The SF-12 And The SF-36 Among Ischaemic Heart Disease Patients

The stated goals of many health and social care interventions or programmes in the field of ischaemic heart disease reflect an increasing emphasis on patients' quality of life as well as quantity of life. Yet, health-related quality of life or health status is measured rarely in clinical practice and usually only as part of a study or trial. This situation tends to be due to practical reasons such as the limited time available to clinicians during a consultation with a patient, or the desire of the patient to leave the confines of the clinician's surgery as quickly as possible. Therefore, shorter HRQoL instruments which can demonstrate psychometric properties comparable to that of their longer counterparts, are increasingly sought after by clinicians, patients and researchers.

A comprehensive literature review (Dempster \& Donnelly, 2000) of the psychometric properties of instruments used to measure health-related quality of life (HRQoL) among people with ischaemic heart disease concluded that the most appropriate generic measure of HRQoL for use among people with ischaemic heart disease was the Short Form 36 (SF-36). The SF-36 (Ware et al., 1993) has been reduced to an even shorter form - the SF-12 (Ware, Kosinski and Keller, 1998) - in an attempt to facilitate the routine collection of health status information, taking account of the time constraints mentioned above. The SF-12 derives scores on two scales - a physical health component summary scale (PCS) and a mental health component summary scale (MCS). For a sample of people with congestive heart failure the scores on the UK version of the SF-12 PCS and SF-12 MCS have been 
found to be strongly correlated (Jenkinson \& Layte, 1997) and have similar means (Jenkinson et al., 1997) to their counterpart summary scales derived from the SF-36. However, the SF-36 MCS mean score was found to differ significantly from the SF12 MCS mean score (Jenkinson et al., 1997). Since these studies were conducted, the US-derived version of the SF-12 has been accepted as the standard version and has been shown to produce similar results to several country-specific versions of the SF12 (Gandek et al., 1998). This means that the scoring formulae (based on regression weights) used to calculate scores on the UK version of the SF-12 are no longer used.

The standard version of the SF-12 has been shown to be reliable and valid among cardiac and stroke patients (Lim \& Fisher, 1999) but no studies exist which compare the SF-12 summary scales with the SF-36 summary scales among a group of patients with ischaemic heart disease.

The aim of this study was to compare the summary scores obtained on the SF12 and the SF-36 for a group of ischaemic heart disease patients, in order to determine whether or not the shorter questionnaire could be used instead of the SF-36 without a significant loss of information.

Method

A total of 119 newly admitted patients to a tertiary referral centre in Northern Ireland between March and June 1999 who were assessed and diagnosed by consultant cardiologists as having ischaemic heart disease were asked, at hospital, for 
their consent to participate in the study. Only two patients ( 1 male, 1 female) refused to participate. The research worker administered the SF-36, incorporating the SF-12, to the consenting participants in a one-to-one interview format, as part of a larger study. As there is no fully developed method for dealing with missing values for the SF-12, anyone who did not complete these 12 items was excluded from the study. A total of 12 patients ( 7 males, 5 females) did not complete the interview, for a variety of reasons - they became too unwell to continue; they had difficulty comprehending the questions; the interview was terminated by the hospital staff, as the patient was due to be taken to the operating theatre; or the interview was terminated by the patient for other reasons such as the arrival of their family. As patients were in hospital for approximately 2 - 3 days in most cases, repeat interviews were often not possible.

A total of 105 patients were interviewed in hospital (89/105) within 3 hours before or as soon as possible after their hospital intervention, or at a hospital-based cardiac rehabilitation class (16/105).

Results

The main reason for admission to the hospital was either myocardial infarction $(31 \% ; 32 / 105$ of patients) or a history of angina $(57 \% ; 60 / 105$ of patients). Another $12 \%(13 / 105)$ of patients were admitted to hospital for other reasons, such as abnormal blood pressure or irregularities discovered in routine medical checks (for example, an electrocardiograph). The majority of patients (53\%) underwent an angiogram during their hospital stay, about $21 \%$ underwent percutaneous transluminal coronary angioplasty and a further $7 \%$ had a coronary artery bypass graft. The patient 
characteristics are presented in Table 1 . The patients in the present study were similar to participants in previous studies in terms of their age (Cupples, McKnight, O'Neill \& Normand, 1996; Lukkarinen \& Hentinen, 1997), sex (Billing, Hjemdahl \& Rehnqvist, 1997; Kee, McDonald \& Gaffney, 1997) and body mass index (OXCHECK, 1995).

The descriptive statistics for each scale are given in Table 2. The patients scored lower than the population norms (which are a mean of 50 and a standard deviation of 10) on the SF-12 and SF-36 PCS but their average SF-12 and SF-36 MCS scores and the standard deviations were similar to the population norms.

There was a strong and significant correlation between the PCS scores for the SF-36 and the SF-12 $(r=0.95 ; p<0.001)$ and between the MCS scores for the SF-36 and the SF-12 $(\mathrm{r}=0.95 ; \mathrm{p}<0.001)$, as indexed by Pearson's product moment correlation coefficient. Additionally, paired t-tests revealed that there were no significant differences between the two questionnaires in terms of the MCS or PCS scores (see Table 3 ). Table 3 also shows that the limits of agreement, as defined by Bland and Altman (1986), of the SF-12 and the SF-36 summary scores are less than 1 standard deviation of these summary scale scores in the general population. Tables 4 and 5 demonstrate that the SF-12 was able to discriminate equally as well as the SF36 between patients grouped on the basis of their responses to a single-item measure of health or between the different angina classifications (as indexed by a KruskalWallis test). 


\section{Discussion}

The aim of this paper was to compare the summary scores derived from the SF-36 and the SF-12. Correlation analysis showed that the MCS scores on the SF-12 were strongly related to the MCS scores on the SF-36 and the PCS scores on the SF12 were strongly related to the PCS scores on the SF-36. It is important and useful to know that these scores are related as it confirms that the two instruments are likely to be measuring the same concepts. However, if we wish to replace the SF-36 with the SF-12, it is not enough to show that their scores are related; there also needs to be an exploration of the extent of the difference between the two instruments.

The results of this study demonstrated that there were non-significant differences between the SF-12 and the SF-36 in terms of their respective summary scales. Although it is acknowledged that the results are based on a small sample, and that a larger sample could have identified significant differences between the SF-12 and SF-36 scales, post hoc power analyses found that there were very small effect sizes between the scales and, for example, a sample size of approximately 750 would have been required to detect a significant difference between the MCS scales. There is very little information about the size of difference that should be considered clinically meaningful when using the SF-12 among cardiac patients. Lim and Fisher (1999) initially suggested $50 \%$ of the standard deviation, but after reviewing the data from almost 2,500 patients, they suggested that a difference in the region of $20 \%$ of the standard deviation should be considered as clinically important. The mean difference between the SF-12 and the SF-36 in this study represented approximately $10 \%$ of the standard deviation for the MCS scale and just under $20 \%$ of the standard deviation for 
the PCS scale. Therefore, the present results show that the differences between the group means of the SF-12 and the SF-36 are not clinically meaningful. Nevertheless, the results show also that individual scores from the SF-12 should not be compared directly with individual scores from the SF-36, because the limits of agreement between the SF-12 and the SF-36 exceed the threshold of what is considered as clinically meaningful. In other words, where the SF-36 is already being used to monitor the outcome of an individual patient, it should not be replaced by the SF-12.

When the sample was divided into subgroups according to self-reported health state or angina classification, the scores within each subgroup were similar between the SF-36 and the SF-12. Moreover, when reduced from 36 to 12 items, the MCS and PCS scales do not appear to be any less powerful in detecting differences between the subgroups already mentioned. However, the size and nature of the sample results in an uneven distribution of the sample across subgroups, with very small numbers in some of the subgroups (as shown in Tables 4 and 5). Therefore, caution is advised when extrapolating the conclusions of this study to particular subgroups not well represented within this study, especially those who describe their health as excellent or poor. Indeed, this type of subgroup analysis would benefit from further research with a larger sample.

A few cautionary notes about the SF-12 also are required. Firstly, 12 of the patients had to be excluded from this study because they did not supply complete data for the SF-12. Yet, SF-36 scores could have been calculated for these patients because of the well-established procedures for dealing with missing data on the SF-36. Therefore, the SF-36 may provide more usable data than the SF-12, which is 
especially important when dealing with small samples, as is the case with the present study. Secondly, the SF-12 only gives 2 summary scores, whereas the SF-36 can be further divided into 8 different scale scores. The SF-36 provides more information but this may not be required for routine data collection. Finally, work is needed to examine the relationship between the SF-12 and disease-specific measures of healthrelated quality of life and whether this relationship reflects that of the SF-36 and disease-specific instruments.

In conclusion, when administered to a group of patients with ischaemic heart disease, the MCS and PCS summary scores derived from the SF-12 are strongly correlated with and closely resemble the MCS and PCS summary scores derived from the SF-36. The discriminatory power of these summary scales are unaffected by their reduction from 36 to 12 items. Therefore, subject to further subgroup analyses with larger sample sizes, the SF-12 is recommended for routine collection of health-related quality of life information among ischaemic heart disease patients because of its brevity, acceptability to patients and, at least comparable psychometric qualities to the 36 item version. 


\section{References}

Billing, E., Hjemdahl, P. \& Rehnqvist, N. (1997). Psychosocial variables in female vs male patients with stable angina pectoris and matched healthy controls. European Heart Journal, 18, 911- 918.

Bland, J.M. \& Altman, D.G. (1986). Statistical methods for assessing agreement between two methods of clinical measurement. Lancet, I, 307-310.

Cupples, M., McKnight, A., O'Neill, C. \& Normand, C. (1996). The effect of personal health education on the quality of life of patients with angina in general practice. Health Education Journal, 55, 75-83.

Dempster, M. \& Donnelly, M. (2000). Measuring health-related quality of life among people with ischaemic heart disease. Heart, 83, 641-644.

Gandek, B., Ware, J.E., Aaronson, N.K., Apolone, G., Bjorner, J.B., Brazier, J.E., Bullinger, M., Kaasa, S., Leplege, A., Prieto, L. \& Sullivan, M. (1998). Crossvalidation of item selection and scoring for the SF-12 Health Survey in nine countries: Results from the IQOLA Project. Journal of Clinical Epidemiology, 51, 1171-1178. 
Jenkinson, C. \& Layte, R. (1997). Development and testing of the UK SF-12. Journal of Health Services Research and Policy, 2, 14-18.

Jenkinson, C., Layte, R., Jenkinson, D., Lawrence, K., Petersen, S., Paice, C. \& Stradling, J. (1997). A shorter form health survey: can the SF-12 replicate results from the SF-36 in longitudinal studies? Journal of Public Health Medicine, 19, 179-186.

Kee, F., McDonald, P. \& Gaffney, B. (1997). Risks and benefits of coronary angioplasty: the patient's perspective: a preliminary study. Quality in Health Care, 6 , 131-139.

Lim, LL-Y. \& Fisher, J.D. (1999). Use of the 12-item Short-Form (SF-12) health survey in an Australian heart and stroke population. Quality of Life Research, 8, 1-8.

Lukkarinen, H. \& Hentinen, M. (1997). Assessment of quality of life with the Nottingham Health Profile among patients with coronary heart disease. Journal of Advanced Nursing, 26, 73-84.

OXCHECK study group of the Imperial Cancer Research Fund. (1995). Effectiveness of health checks conducted by nurses in primary care: final results of the OXCHECK study. British Medical Journal, 310, 1099-104. 
Ware, J.E., Kosinski, M. \& Keller, S.D. (1998). SF-12: How to Score the SF-12

$\underline{\text { Physical and Mental Health Summary Scales. }}$ ( ${ }^{\text {rd }}$ ed). Lincoln, RI: QualityMetric Incorporated.

Ware, J.E., Snow, K.K., Kosinski, M.K. \& Gandek, B. (1993). SF-36 Health Survey

Manual and Interpretation Guide. Boston, MA: The Health Institute, New England Medical Center. 
Table 1: Patient characteristics

Age: mean (sd)

$59.83(9.82)$

Sex: male:female

$77: 28$

Time of ischaemic heart disease: median (range)

6 months

( 2 days to 42 years)

Body mass index: mean (sd)

$27.10(4.36)$

Canadian Cardiovascular Society Classification of Angina

No chest pain

$35 / 105(33.3 \%)$

Class I

$11 / 105(10.5 \%)$

Class II

$21 / 105(20.0 \%)$

Class III

$14 / 105(13.3 \%)$

Class IV

$24 / 105(22.9 \%)$ 
Table 2: Descriptive statistics for the summary scales

\begin{tabular}{lccccc}
\hline Scale & Mean & Standard Deviation & Median & Minimum & Maximum \\
\hline SF-36 PCS & 40.86 & 11.64 & 42.13 & 12.81 & 60.17 \\
SF-12 PCS & 40.19 & 11.28 & 40.30 & 16.27 & 57.76 \\
& & & & & \\
SF-36 MCS & 47.87 & 10.96 & 50.95 & 15.82 & 65.37 \\
SF-12 MCS & 48.32 & 10.38 & 51.20 & 18.08 & 64.58 \\
\hline
\end{tabular}


Table 3: Differences between the SF-12 and SF-36 summary scales

\begin{tabular}{lccccc}
\hline Scales & Mean & Std Dev & $95 \%$ CI & t & p \\
\hline SF-12 PCS - SF-36 PCS & -0.67 & 3.51 & -1.35 to 0.08 & -1.96 & 0.05 \\
Limits of agreement & & & -7.69 to 6.35 & & \\
SF-12 MCS - SF-36 MCS & 0.45 & 4.42 & -0.20 to 1.09 & 1.37 & 0.17 \\
Limits of agreement & & & -8.39 to 9.29 & & \\
& & & & & \\
\end{tabular}


Table 4: SF-12 and SF-36 mean scores grouped by patients' self-reported health state

\begin{tabular}{lcccccc}
\hline $\begin{array}{l}\text { In general would you } \\
\text { say your health is: }\end{array}$ & $\begin{array}{c}\text { Excellent } \\
(\mathrm{n}=8)\end{array}$ & $\begin{array}{c}\text { Very good } \\
(\mathrm{n}=31)\end{array}$ & $\begin{array}{c}\text { Good } \\
(\mathrm{n}=45)\end{array}$ & $\begin{array}{c}\text { Fair } \\
(\mathrm{n}=14)\end{array}$ & $\begin{array}{c}\text { Poor } \\
(\mathrm{n}=7)\end{array}$ & $\mathrm{p}$ \\
\hline SF-36 PCS & 50.23 & 44.51 & 42.46 & 26.38 & 30.42 & 0.006 \\
SF-12 PCS & 49.72 & 43.93 & 41.94 & 26.19 & 27.18 & $<0.001$ \\
& & & & & & \\
SF-36 MCS & 54.88 & 51.70 & 47.75 & 45.76 & 27.70 & 0.005 \\
SF-12 MCS & 54.88 & 52.29 & 48.21 & 44.87 & 30.39 & 0.007 \\
\hline
\end{tabular}


Table 5: SF-12 and SF-36 mean scores grouped by Canadian Cardiovascular Society Classification of Angina

\begin{tabular}{lcccccc}
\hline CCSCA: & $\begin{array}{c}\text { No chest pain } \\
(\mathrm{n}=35)\end{array}$ & $\begin{array}{c}\text { Class I } \\
(\mathrm{n}=11)\end{array}$ & $\begin{array}{c}\text { Class II } \\
(\mathrm{n}=21)\end{array}$ & $\begin{array}{c}\text { Class III } \\
(\mathrm{n}=14)\end{array}$ & $\begin{array}{c}\text { Class IV } \\
(\mathrm{n}=24)\end{array}$ & $\mathrm{p}$ \\
\hline SF-36 PCS & 41.07 & 40.50 & 33.54 & 34.75 & 26.37 & $<0.001$ \\
SF-12 PCS & 41.76 & 39.84 & 31.20 & 38.74 & 26.71 & $<0.001$ \\
& & & & & & \\
& & & & & & \\
SF-36 MCS & 52.13 & 51.60 & 50.23 & 53.35 & 50.28 & 0.079 \\
SF-12 MCS & 51.73 & 51.22 & 49.41 & 51.17 & 50.24 & 0.015 \\
\hline
\end{tabular}

